\title{
THE EFFECT OF EXERCISE AND BODY POSITION ON THE VENOUS PRESSURE AT THE ANKLE IN PATIENTS HAVING VENOUS VALVULAR DEFECTS ${ }^{1}$
}

\author{
By ALBERT A. POLLACK,2 BOWEN E. TAYLOR,2 THOMAS T. MYERS, \\ AND EARL H. WOOD \\ (From the Divisions of Medicine, Postoperative Care and Physiology', Mayo Foundation \\ and Mayo Clinic, Rochester, Minn.)
}

(Received for publication December 4, 1948)

The purpose of this investigation was to determine directly and record continuously the effects of body position and of walking on the venous pressure at the ankle in patients having incompetent veins of the lower extremity. Smirk (1), in 1936, reported the first direct measurement of venous pressure at the ankle during walking. His measurements were made on one normal subject. Beecher, Field and Krogh (2), in the same year, reported on the indirect measurement of the venous pressure in the human leg during walking. Others (3-7) have reported the effects of exercise and position on the venous pressure in the leg measured both by direct and by indirect methods. Recently Pollack and Wood $(8,9)$, and Henry $(10)$ have given preliminary reports of direct studies of venous pressure in the human leg during walking.

In the present study the venous pressure was recorded photographically by means of an electrical strain-gauge manometer (11). ${ }^{3}$ The manometer was attached to the subject's lower extremity by means of a specially constructed aluminum support that was taped to the lateral surface of the leg. Care was taken that no tape was placed over the vein to be used for measurement of the pressures. The manometer was coupled to this aluminum support with two double-ended universal clamps (Figure 1).

Polythene tubing $15 \mathrm{~cm}$. long with an internal diameter of approximately $0.5 \mathrm{~mm}$. was used as a venous catheter. ${ }^{4}$ A venipuncture was performed with a number 17 needle in the great saphenous vein as it passes anterior to the medial malleolus. The catheter was passed through the

\footnotetext{
1 The authors wish to acknowledge the professional assistance of Dr. John E. Osborn and the technical assistance of Mr. R. L. Engstrom and Miss M. E. Clark in the conduct of these studies.

2 Fellows in Medicine, Mayo Foundation.

3 Manufactured by Statham Laboratories, Los Angeles, Calif.

4 Manufactured by Surprenant Electrical Insulation Co., Boston 7, Massachusetts.
}

needle into the vein for a distance of about $10 \mathrm{~cm}$.; then the needle was withdrawn, leaving the catheter in place. The manometer system was flushed frequently with heparinized saline solution.

Respiration was recorded by means of a thermocouple mounted in a plastic nose piece. The heart rate and the electrocardiogram were measured through a Sturm and Wood cardiotachometer (12).

The venous pressure was recorded continuously in the supine, sitting and resting standing positions. After these maneuvers the patient walked on a horizontal powerdriven treadmill at 1.7 m.p.h. for periods ranging from 15 to 60 seconds.

The vertical distance between the tip of the catheter and the third thoracic interspace was measured in the sitting and standing positions. The hydrostatic pressure exerted by a column of blood extending over this distance was calculated, 1.06 and 13.55 being used as the specific gravity of blood and mercury respectively. The zero base lines in the sitting and standing positions were determined by recording the pressure when the surface of a column of fluid in a tube $(1 \mathrm{~cm}$. internal diameter) connected to the catheter was held on the surface of the leg level with the position which had been occupied by the catheter tip in the lying, sitting and standing positions. This procedure was necessary in order to avoid errors due to capillarity of the catheter.

\section{RESULTS}

In the supine position the average venous pressure in seven patients with primary varicose veins ${ }^{5}$ was $7.2 \mathrm{~mm}$. of mercury with a range from 5.7 to $8.5 \mathrm{~mm}$. In six patients with incompetent superficial (greater saphenous) veins associated with a history of previous iliofemoral thrombophlebitis ${ }^{6}$ the average venous pressure was $10.7 \mathrm{~mm}$. with a range from 8.3 to $14 \mathrm{~mm}$. of mercury in the supine position. In the sitting position the average venous pressure at the ankle in ten patients with

\footnotetext{
5 This term has been used to indicate uncomplicated varicosities of the greater saphenous system.

6 These patients clinically appeared to have chronic venous insufficiency of the deep veins in addition to varicosities of the superficial system.
} 


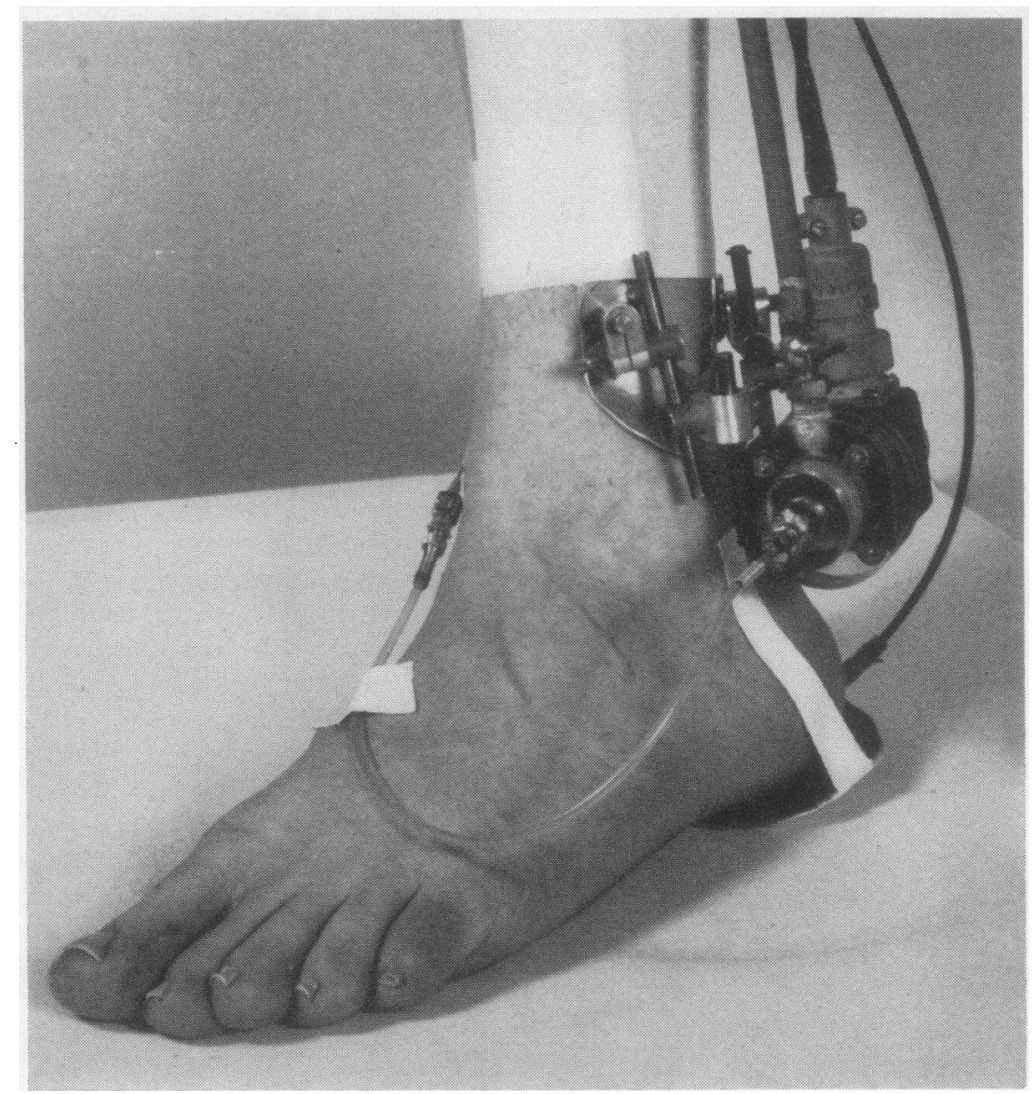

Fig. 1. Strain-Gauge Manometer Attached to the Ankle

incompetent veins of the lower extremity was 52 $\mathrm{mm}$. of mercury with a range from 31 to $61 \mathrm{~mm}$. The average venous pressure at the ankle in the resting standing position was $81.9 \mathrm{~mm}$. of mercury with a range from 63 to $97 \mathrm{~mm}$. (Table I).

In the sitting position, the average difference between the measured venous pressure and the calculated hydrostatic pressure of a column of blood extending from the third thoracic interspace to the ankle was $0.3 \mathrm{~mm}$. of mercury. In the standing position, this difference was $0.6 \mathrm{~mm}$. (Table $\mathrm{I}$ ). It is evident that while the patient is at rest in the sitting or standing position the venous pressure at the ankle is sufficient to support a column of blood approximately up to the third thoracic interspace, the level of the middle of the right atrium (13).

In seven patients who had primary varicose veins, walking at 1.7 m.p.h. uniformly produced a decrease in the mean venous pressure at the ankle averaging $37.4 \mathrm{~mm}$. of mercury with a range from 29.5 to $47.4 \mathrm{~mm}$., which was maintained for the duration of the 30-second to 60 -second period of walking (Table II). In six patients who had incompetent greater saphenous veins and a history of previous iliofemoral thrombophlebitis, walking produced an average fall of only $11.1 \mathrm{~mm}$. of mercury in the mean venous pressure at the ankle (Table III). The decrease in venous pressure at the ankle in normal subjects produced by walking $1.7 \mathrm{~m}$.p.h. averaged 64 and ranged from 54 to $71 \mathrm{~mm}$. of mercury.

In the patients who had uncomplicated greater saphenous vein incompetency the average time required for the venous pressure to return to the resting standing level after the walk was completed was 2.8 (1.2 to 5.5 ) seconds as contrasted to the 31 ( 8 to 57 ) seconds required in normal subjects (9) (Figure $2 a$ and $b$ ).

In the normal subjects after the initial one or two steps of walking the maximal venous pressures generated during subsequent steps of the walk were considerably less than the control resting standing pressure (Figure 2a) (9). In patients who had 
TABLE I

Comparison of venous and hydrostatic pressures at the ankle in patients who had incompetent veins of the lower exiremity when in the seated and standing positions

\begin{tabular}{|c|c|c|}
\hline Patient & $\begin{array}{l}\text { Measured venous } \\
\text { pressure, } \\
\text { mm. of mercury }\end{array}$ & $\begin{array}{l}\text { Calculated hydro- } \\
\text { static pressure, } \\
\boldsymbol{m m} \text {. of mercury }\end{array}$ \\
\hline & Seated & Seated \\
\hline $\begin{array}{r}1 \\
2 \\
3 \\
5 \\
6 \\
7 \\
8 \\
9 \\
10\end{array}$ & $\begin{array}{l}60 \\
61 \\
31 \\
50 \\
50 \\
54 \\
52 \\
55 \\
55\end{array}$ & $\begin{array}{l}58 \\
61 \\
34 \\
50 \\
51 \\
54 \\
53 \\
55 \\
55\end{array}$ \\
\hline Average & 52 & 52.3 \\
\hline \multirow[t]{2}{*}{ Normal subjects* } & $\begin{array}{c}58.8 \\
(55-64)\end{array}$ & $\begin{array}{c}60.2 \\
(55-66)\end{array}$ \\
\hline & Standing & Standing \\
\hline $\begin{array}{r}1 \\
2 \\
3 \\
4 \\
5 \\
6 \\
7 \\
8 \\
9 \\
10 \\
11\end{array}$ & $\begin{array}{l}86 \\
89 \\
63 \\
97 \\
71 \\
82 \\
84 \\
82 \\
83 \\
84 \\
80\end{array}$ & $\begin{array}{l}87 \\
89 \\
63 \\
97 \\
72 \\
84 \\
84 \\
82 \\
85 \\
84 \\
80\end{array}$ \\
\hline Average & 81.9 & 82.5 \\
\hline Normal subjects* & $\begin{array}{c}90.5 \\
(88-97)\end{array}$ & $\begin{array}{c}92.5 \\
(88-100)\end{array}$ \\
\hline
\end{tabular}

* Average and extreme values obtained in five normal subjects (9).

uncomplicated valvular defects of the greater saphenous system, the maximal pressure exerted during the stable period approached and frequently equaled the resting standing pressure (Figure $2 b$ ). In the patients who had incompetency of the greater saphenous vein and a previous iliofemoral thrombophlebitis the maximal pressure during each step usually exceeded the hydrostatic pressure throughout the period of walking. In these patients the maximal venous pressure during the steps within the stable pressure period of the walk averaged $29 \mathrm{~mm}$. of mercury greater than the resting standing value (Figure $2 c$ ). After walking, the venous pressure at the ankle in normal subjects and patients who had uncomplicated greater saphenous incompetency returned to the resting
TABLE II

Venous pressure at the ankle in patients who had simple greater saphenous vein incompetency during quiet standing and while walking at 1.7 m.p.h.

\begin{tabular}{c|c|c|c}
\hline & \multicolumn{2}{|c|}{ Mean venous pressure, mm. of mercury } \\
\cline { 2 - 4 } Patient & $\begin{array}{c}\text { Quiet } \\
\text { standing } \\
(\mathrm{A})\end{array}$ & $\begin{array}{c}\text { Walking } \\
1.7 \text { m.p.h. } \\
(\mathrm{B})\end{array}$ & $\begin{array}{c}\text { Decrease in } \\
\text { pressure } \\
(\mathrm{A}-\mathrm{B})\end{array}$ \\
\hline 1 & $\mathbf{7 1}$ & 34 & 37 \\
2 & 81.9 & 34.5 & 47.4 \\
3 & 84.3 & 45 & 39.3 \\
4 & 81 & 41 & 40 \\
5 & 85 & 49.6 & 35.4 \\
6 & 85.5 & 56 & 29.5 \\
7 & 79 & 46 & 33 \\
\hline Average & 81.1 & 43.7 & 37.4 \\
\hline Normal subjects* & 86.6 & 22.3 & 64.3 \\
& $(79-92)$ & $(11-31)$ & $(54-71)$ \\
\hline
\end{tabular}

* Average and extreme values obtained in 11 normal subjects (9).

standing control level, while in those patients who had greater saphenous incompetency as well as a previous iliofemoral thrombophlebitis the pressure increased to an average of $3 \mathrm{~mm}$. of mercury higher than the resting standing control level within one second after the completion of the walk and then gradually decreased within a period of 60 seconds to the original control pressure.

\section{COM MENT}

In the resting sitting and standing positions in normal subjects as well as in patients who have venous insufficiency the venous pressure at the ankle is equal to the hydrostatic pressure of a col-

TABLE III

Venous pressure at the ankle in patients who had greater saphenous vein incompetency and a history of iliofemoral thrombophlebitis, during quiet standing and while walking 1.7 m.p.h.

\begin{tabular}{c|c|c|c|c}
\hline \hline & \multicolumn{3}{|c}{ Mean venous pressure, mm. of mercury } \\
\cline { 2 - 5 } Patient & $\begin{array}{c}\text { Quiet } \\
\text { standing, } \\
\text { start (A) }\end{array}$ & $\begin{array}{c}\text { Quiet } \\
\text { standing, } \\
\text { end }\end{array}$ & $\begin{array}{c}\text { Walking } \\
1.7 \text { m.p.h. } \\
(\mathrm{B})\end{array}$ & $\begin{array}{c}\text { Decrease in } \\
\text { pressure } \\
(\mathrm{A}-\mathrm{B})\end{array}$ \\
\hline 8 & 86 & 87 & 69 & 17 \\
9 & 86 & 89 & 73.5 & 12.5 \\
10 & 62 & 64 & 47 & 15 \\
11 & 96 & 104 & 85 & 11 \\
12 & 102 & 102 & 96 & 6 \\
13 & 94 & 99 & 89 & 5 \\
\hline Average & 87.7 & 90.8 & 76.6 & 11.1 \\
\hline
\end{tabular}




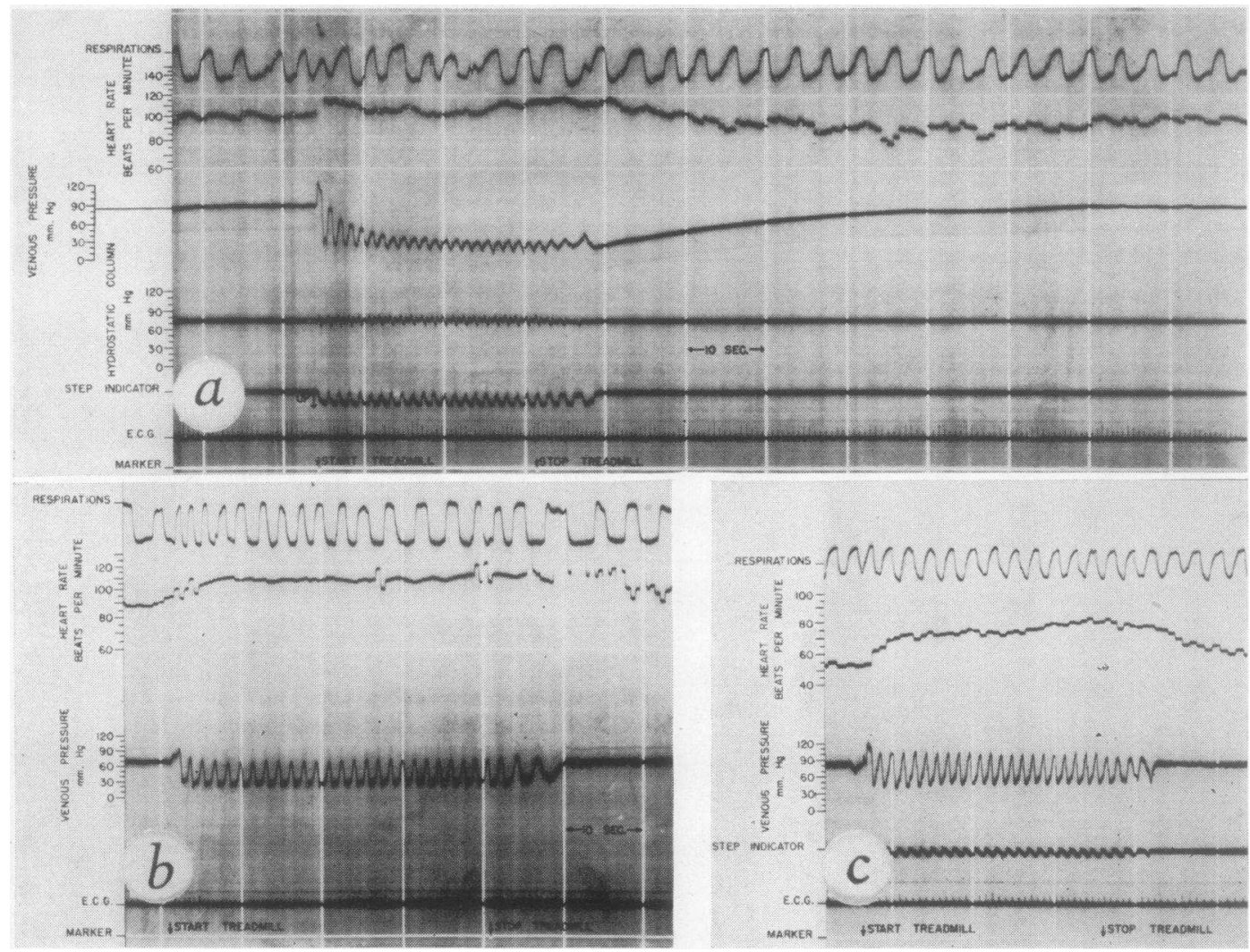

Fig. 2. Effect of Walking 1.7 M.P.h. on the Venous Pressure at the Ankle

a. Normal subject. b. Patient who had primary varicose veins. $c$. Patient who had incompetent greater saphenous vein and a history of iliofemoral thrombophlebitis.

umn of blood up to the level of the right atrium $(1,5-10)$. The decrease of venous pressure at the ankle in normal subjects produced by walking on a horizontal treadmill is due to the pumping action of the muscles and the competency of the venous valves in preventing reflux of blood into the emptied segments of the veins during the period of muscular relaxation (9). In patients who have uncomplicated primary varicose veins, the valves are unable to prevent the return flow of blood during muscular relaxation and the venous pressure returns relatively quickly to the hydrostatic level, thus accounting for the higher mean pressure during the walk and rapid return to the hydrostatic control level after the walk has been completed.

Interpretation of the genesis of the venous pressure tracings obtained from patients who have incompetent great saphenous veins and a history of previous iliofemoral thrombophlebitis is un- certain. At first it would appear that there was interference with the outflow of venous blood from the leg in this condition. The higher resting standing pressure at the end of the walk than at the beginning, the higher mean pressure during the stable period, and the marked rise above hydrostatic levels during each step of the stable walking period as contrasted to those obtained from patients having primary varicose veins point to this explanation. However, the fact that no significant difference was found between the extremes of pressures of the individual steps during walking in patients who had primary varicose veins and in patients who had incompetency of the superficial system and a history of iliofemoral thrombophlebitis does not support this interpretation. Even with a critically damped manometer system the effects of acceleration generated by the motions of walking on the manometer and hydrostatic systems are difficult to control. Therefore, the sig- 
nificance of the contours and extremes of the pressure variations recorded during walking is difficult to assess. The use of mean pressures, as determined by planimetry, is much less subject to criticisms of this type.

The fact that in four patients suffering from cardiac disease, who had elevated resting standing venous pressure at the ankle due to cardiac causes, the venous pressure at the ankle decreased during walking to the same range as in normal subjects indicates that the venous valves and the action of voluntary muscles have more to do with the regulation of venous pressure in the leg than does central venous pressure (14).

It is not inconceivable that determinations of venous pressure at the ankle during exercise may be used as a diagnostic aid, and as a means of assaying the efficacy of surgical treatment of abnormalities in the venous systems of the leg.

\section{SUMMARY AND CONCLUSIONS}

Venous pressure in the greater saphenous vein at the ankle was studied in 13 patients with varicose veins while resting in the recumbent, seated and standing positions and while walking on a treadmill.

Confirmatory data were obtained indicating that the venous pressure at the ankle in the resting, sitting or standing positions in normal subjects and patients with incompetency of the saphenous veins is sufficient to support a column of blood to approximately the level of the third thoracic interspace.

Walking on a level treadmill at 1.7 miles per hour produced an average decrease in mean venous pressure at the ankle of 37 (30 to 47 ) $\mathrm{mm}$. of mercury in seven patients with primary varicose veins and 11 ( 5 to 13 ) $\mathrm{mm}$. of mercury in six patients with varicose veins associated with a history of a previous iliofemoral thrombophlebitis. In normal subjects this value was 64 (54 to 71 ) $\mathrm{mm}$. of mercury.

In patients who had uncomplicated incompetency of the greater saphenous vein the average time required for the venous pressure to return to the resting standing level after cessation of walking was 2.8 (1.2 to 5.5) seconds. In those patients with a history of previous iliofemoral thrombophlebitis the pressure rose to levels slightly in excess of the control resting value within one second after completion of the walk as contrasted to the 31 (eight to 57) seconds required for the pressure to return to the control values after walking in normal subjects.

These data are in harmony with the concept that the function of the venous valves in conjunction with the action of voluntary muscles is of primary importance in the regulation of venous pressure at the ankle.

\section{BIBLIOGRAPHY}

1. Smirk, F. H., Observations on causes of oedema in congestive heart failure. Clin. Sc., 1936, 2, 317.

2. Beecher, H. K., Field, M. E., and Krogh, A., Effect of walking on venous pressure at ankle. Skandinav. Arch. f. Physiol., 1936, 73, 133.

3. Hooker, D. R., The effect of exercise upon the venous blood pressure. Am. J. Physiol., 1911, 28, 235.

4. Rutledge, D. I., Studies on venous pressure. Thesis, Graduate School, University of Minnesota, 1941, 82 pp.

5. Seiro, Väinö, Über Blutdruck und Blutkreislauf in den Krampfadern der unteren Extremitäten. Acta chir. Scandinav., 1937, 80, 41.

6. Veal, J. R., and Hussey, H. H., Methods for measurement of pressures in antecubital and popliteal veins during exercise. M. Ann. District of Columbia, 1940, 9, 71.

7. Hickam, J. B., and McCulloch, R. P., Normal and impaired function of the superficial leg veins. Program, Twenty-First Sessions, American Heart Association, (June 18 and 19) 1948, pp. 9 and 10.

8. Pollack, A. A., and Wood, E. H., Venous pressure in the human leg during exercise and in various positions. Federation Proc., 1948, 7 (pt. 1, no. 1), 94.

9. Pollack, A. A., and Wood, E. H., A study of venous pressure in the saphenous vein at the ankle in man during exercise and changes in posture. J. Applied Physiol. (In press.)

10. Henry, J. P., Use of the anti-G suit to aid in the relief of fighter pilot discomfort. Memorandum Report, U. S. Air Force No. TSEAA-689-2A, Wright-Patterson Air Force Base, Dayton, Ohio, September 22, 1947.

11. Lambert, E. H., and Wood, E. H., The use of a resistance wire, strain-gage manometer to measure intraarterial pressure. Proc. Soc. Exper. Biol. \& Med., 1947, 64, 186.

12. Sturm, R. E., and Wood, E. H., An instantaneous recording cardiotachometer. Rev. Scient. Instruments, 1947, n.s. 18, 771.

13. Brash, J. C., and Jamieson, E. B., Cunningham's Text-Book of Anatomy. Oxford University Press, New York, 1937, Ed. 7, p. 1145.

14. Pollack, A. A., Wood, E. H., and Burchell, H., Unpublished data. 